\section{Radiofrequency Ablation (RFA) of Pulmonary Metastases: Technical Success vs. Actual Benefit}

\section{TO THE EDITORS:}

I was both excited and disturbed as I read the article by Huo about RFA of pulmonary metastases. ${ }^{1}$ I'm excited for patients because this article adds data on the technical success of RFA of pulmonary metastases. However, as someone devoted to evidence-based care, the lack of attention to the appropriateness of treatment in the first place is disturbing.

The goal of pulmonary metastasectomy is to eradicate all cancer and effect cure. Treatment for palliation (of a specific symptom) is extremely rare. In this study 33\% were treated "palliatively" but apparently without symptoms and without data on symptom relief. The authors apparently assume that treatment is beneficial, even if cure is impossible.

However, no data even suggest that treatment of only some metastases while leaving others behind prolongs survival. As an editor of a comprehensive review of metastasectomy I am familiar with this literature. Furthermore, harm may result, as in the "palliatively treated" patient of Hou et al. who developed a bronchopleural fistula. The authors should justify "palliative" treatment and provide a measure of symptom relief.

Is it possible that treatment of only some metastases in patients with multiple metastases prolongs survival? Whether resection of a renal cell primary tumor prolongs survival of stage IV patients is controversial, but could provide a rationale (but untested with respect to resection of metastases). Huo et al. provide no data to address this question. Patients chosen for metastasectomy are selected as a result of favorable tumor biology; therefore, comparison with patients not selected for this approach is inappropriate. The natural history of patients with isolated metastases may be prolonged, and the mere occurrence of 5-year survival after metastasectomy does not necessarily prove that the treatment made any difference. ${ }^{2}$

Misuse of a good technology can result in a negative perception and cause technology that is valuable when used appropriately to be abandoned. Furthermore, treatment (especially if minimally invasive) may have irresistible emotional appeal. We must resist the temptation to do something just because we can. We must be careful to use technology appropriately and evaluate it carefully in order to realize true benefits for our patients.

\section{Frank C. Detterbeck, MD}

Section of Thoracic Surgery, Yale University School of Medicine, New Haven, CT

e-mail: Frank.detterbeck@yale.edu

Published Online: 12 January 2010

(C) Society of Surgical Oncology 2010

\section{REFERENCES}

1. Huo ASY, Morris DL, King J, Glenn D. Use of percutaneous radiofrequency ablation in pulmonary metastases from renal cell carcinoma. Ann Surg Oncol. 2009;16:3169-75.

2. Aberg T, Malmberg KA, Nilsson B, Nöu E. The effect of metastasectomy: fact or fiction? Ann Thorac Surg. 1980;4:378-84. 